\title{
Education Model Based on Life Skill
}

\section{(a Meta-Synthesis)}

\author{
Aswin Bancin \\ Post Graduate Program of Uninversitas Negeri Medan \\ Medan, Indonesia \\ aswinbancin@umsu.ac.id
}

\author{
Biner Ambarita \\ Post Graduate Program of Uninversitas Negeri Medan \\ Medan, Indonesia \\ binerambarita@gmail.com
}

\begin{abstract}
The problems that will be examined in this study are (1) How the concept of education based on life skills (2) How education management based on life skills (3) How the education management model based on life skills. This research was carried out in the form of meta-synthesis, also referred to as systematic review, a research to identify, evaluate and interpret the result of similiar studies to answer research questions, spesific topics or phenomena that are concern. Form such data will be identified, analyzed and interpreted to produce conclusion. In this study the author will be conduct a meta synthesis (identifying, evaluating and interpreting) 13 research journals based on life skills education, so that the authors get new concepts or deep new insights about Life Skills-Based Education Models. The author will conclude a lot of information from 13 journals that may conflict with each other or support each other which then can increase the streght of the authors analysis., overcome uncertainties and also be able to answer questions about the life skills education model proposed in previous studies. The education model based on life skills through training can make positive decisions in the face of everyday.
\end{abstract}

Keywords: education, life skill, meta-synthesis

\section{INTRODUCTION}

Basically, life skills is a knowledge and ability possessed by someone in dealing with various problems in everyday life, and effectively trying to find various solutions to solve problems faced, through creativity and proactively to be interacted directly with environmental conditions and surrounding community. The WHO Department of Mental Health have identified five basic areas of life skills that are relevant across cultures, that is decision-making and problemsolving; creative thinking and critical thinking; communication and interpersonal skills; self-awareness and empathy; and coping with emotions and coping with stress.

Life skill can be obtained through an educational process, both formal and informal. Family education and social environment is a form of non-formal education in life skills education. The education in schools is formal education which is followed through life skills education programs that have been arranged in a structured and systematic manner. Life skills education is an implementation of one's values, behavior and actions towards the conditions of the problems encountered in daily life. Where he is expected to be capable, competent, and skilled in completing, because of the purpose of like skill education to promote mental well being and competence in young people as they face the realities of life (Gulhane, 2014).

Furthermore, according to the Ministry of National Education (2002) the objectives of life skills education are: first, to actualize the potential of students so that they can be used to solve the problems faced; second, provide opportunities for schools to develop flexible learning, in accordance with broad-based education principles; and third, optimizing the use of school environment resources, by providing opportunities for the use of resources in the community, in accordance with the principles of school-based management.

Life skills education always emphasizes the understanding of the values of life faced in real life. Therefore, life skills education must be able to provide an educational content that has a direct relationship to the values of everyday life in real terms. Research on life skills education has been carried out by experts and researchers in an effort to provide concepts, models, images, solutions and basic capital for a person in facing various increasingly competitive life problems. So that the problems faced can be overcome effectively and comprehensively. However, generally research in life skills education is more focused on students so that they are able to face various problems in real life, when completed through the formal education process.

The effectiveness of the life skills education process, basically, relates to concepts, management and models that are in accordance with the conditions faced by a person in everyday life. Therefore, the purpose of this paper is toexamine three things.First, analyze the the concept of education based on life skill. Second, analyze education management based on life skill. Third, analyze the education model based on life skill.

\section{LITERATURE REVIEW}

\section{A. Life Skill Education}

Life skills are the skills to solve problems in an innovative way using facts, concepts, principles or procedures that have been learned. According to Gulhane (2014), life skills are those abilities which may help on individual to lead a holistic 
and fruitful life, and promote well-being and happiness among young generation. Realizing the importance of the collaborative learning and lessons of life. Life skills help to develop these within the personalities of learners(Kumar, 2017).

Life skills have several common key components, which include behavioral, cognitive, psychosocial and interpersonal competencies that aid individuals to cope with challenges, and develop and succeed in various settings (Nasheeda, et. al., 2019), so that it can enhance human capabilities and prepare the young for the survival and participation in an increasingly skill-based global economy. Life skill lays foundation for life long learning, enabling people to access and process information both in formal and non-formal setting leading to better quality of life (Daisy and Nair, 2018).

Prajapati (2017) have be classified of life skill into three broad categories, i.e.: first,thinking skills: thinking skills are the skill that enhances the logical faculty of the brain using an analytical ability, thinking creatively and critically, and developing problem-solving skills and improving decisionmaking abilities; second,social skills: social skills include interpersonal skills, communication skills, leadership skills, management skills, advocacy skills, co-operation and team building skills, etc; and third,emotional skills: emotional skills, involves, knowing and being comfortable with oneself. Thus, self- management, including managing/coping with feelings, emotions, stress and resisting peer and family pressure.

Meanwhile, UNICEF (2015), UNESCO and WHO, (1999) has classified of life skills in several categories, vis, knowledge, attitude, skills, self-awareness skills; empathy skills; skills of relationships between individuals; effective communication skills; stress coping skills; managing excitement skills; problem solving skills; decision-making skills; creative thinking skills; and critical thinking skills, cognitive skills, social skills and negotiating skills or coping skills.

Education as a process of self-actualization, where an individual tries to actualize and develop all the potential he has. Therefore, education can take place at any time and in any place. Everyone, both children and adults, experiences the process of education through what is encountered or what is done. Education in relation to Life Skills, certainly cannot be separated from the educational process carried out in schools and educational institutions through various life skills education programs.

WHO (1999) stated that life skills education contributes to basic education; gender equality; democracy; good citizenship; child care and protection; quality and efficiency of the education system; the promotion of lifelong learning; quality of life; and the promotion of peace. Where life skills education is aimed at facilitating the development of psychosocial skills that are required to deal with the demands and challenges of everyday life.

Whereas Prajapati (2017) argued,life skills education bridges the gap between basic functioning and capabilities. It strengthens the ability of an individual to meet the needs and demands of the present society and helps in dealing with the above issues in a manner to get desired behavior practical. Imparting life skill training through inculcating life skill education will help youth to overcome such difficulties in life.

Therefore, life skills education is expected to make learners of good moral character, discipline, behaviour, and cooperation, education should be able to incorporate certain qualities within the learners. These qualities can transform students and modify them into better adjusted and emotionally intelligent people. These qualities are a part of life skills and a good life skills training can make the foundation of these virtues and habits. Life skills help individuals and communities to solve problems, make informed decisions, think critically and creatively, empathize with others, communicate effectively, build healthy relationships, and cope with and manage life in a productive manner (Kumar, 2017).

In the view of UNICEF (2015), the goal of life skills education is to equip individuals with appropriate knowledge on risk taking behaviours and develop skills such as communication, assertiveness, self-awareness, decisionmaking, problem solving, critical and creative thinking to protect them from abuse and exploitation.

\section{B. The Concept of Education Based on Life Skill}

The concept is an abstraction of an idea or mental picture, expressed through a word or symbol. Life skills education is an educational concept that aims to provide provisions and prepare students to have the courage and ability to deal with various problems of life and life well without feeling depressed and bored, then to try creatively and proactively to find solutions, so that problems are able to be overcome.

In the concept of life skills as mandated in UUSPN No. 20 in 2003 and PP 19 in 2005, and which have been developed previously, that is Generic Life Skills and Specific Life Skills. For generic life skills consisting of personal skills and social skills. Where personal skills include skills in understanding themselves and thinking skills. Whereas social skills include communication skills and cooperative skills. Meanwhile, specific life skills are the skills to deal with certain jobs or circumstances. Academic or intellectualskills related to the field of work which requires more intellectual thought or work. Vocational skills are related to areas of work that require more motor skills. The concept of life skills can be stated in the picture as follows: 


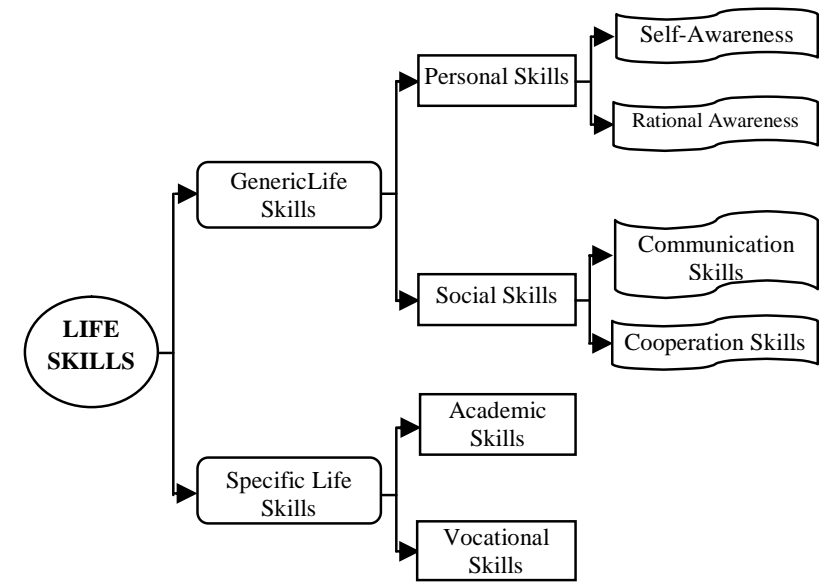

Fig. 1. Modification of The Concepts of Life Skills

On the other hand, ELT (2019) uses the concept of education based on life skill through "play" in developing life competencies. Playis more open-ended and is a pleasurable activity that is primarily concerned with the process not outcome. In The Cambridge Life Competencies Framework was created in response to requests from educators about how all the various skills and competencies that students require in the $21^{\text {st }}$ century through the areas of creative thinking, collaboration, critical thinking, learning to learn, communication, and social responsibilities.

Kumar (2017) states that one can learn life skills from own experiences, insight, perceptions, parents, stories, books, teachers, religion, media, and culture etc. Life skills education is effective for promoting positive social and mental health of adolescents which plays an important role in strengthening coping strategies and developing self-confidence and emotional intelligence, as well as enhancing critical thinking, problem solving and decision making skills.

As for the concept of education based on life skill through "training", where Mishal (2016) found that life skill training of 'training programme' developed was effective on selfesteem of teacher trainees at B.Ed. level, through life skills training can improve self-esteem, self-efficacy and adjustment include self-awareness, effective communication skills, interpersonal relationships, time management, coping stress, managing emotions, creative thinking, critical thinking, empathy and few others.

Meanwhile, in the studie of Behroz-Sarcheshmeh, et al. (2017) found that the effectiveness of life skills training includingcooperation, assertion, and self-control on social skills of high school students with intellectualdisabilities, some students with intellec-tual disability are able to pick up desirable skills through their daily interactions with peers and parent, it is impor-tant that teachers and parents reinforce learning of social behaviors with direct and indirect life skills training.

\section{Education Management Based on Life Skill}

Educational management has been understood as a tool or a technique to organize school work (Souza in Lemos, 2017), called as a science or process which based on resources managing to reach the productive education goal according to the planning effectively and efficiently (Surya, 2011). Kumpulainen et al. (2010) associates it as school administration, whereas Bush (2011) states a field of study and practice concerned with the operation of educa-tional organizations.

The education management based on life skills is arranged based on consideration of the socio-cultural conditions in the educational environment. For the SAARC Countries are in a process of incorporating life skill education in the secondary teacher education curriculum. Theme emphasize the teacher education curriculum in providing life skills learning materials, such as Afghanistan uses an approach through integrated life skills within their curriculum as a subject area in itself. Bangladesh reviewed its secondary school curriculum to identify gaps with respect to LSBE (Life Skills Based Education). Bhutan rearrage mastery on life skill education is being provided to the teachers at the initial teacher education programmes to the four years programmes to make them sound in all respect. India arrage Education Programmes (AEP) should become an integral part of school education and the responsibility of transacting life skill based education to secondary school students are fixed up on secondary teachers. Meldive forming an United Nations Population Fund (UNFPA) supported the Life Skills Education project as a co-curricular activity. Sri Lanka uses an approach Life Competencies Programmes (LCP) are conducted to train the secondary teachers (Munsi, 2014).

Education management in developing lifes skills requares a systematic learning plan. Because of, it can have a positive impact on the development of student achievement. In the research Juwahir (2017) found that plan is more emphasized on thelearning process itself. And the mechanism which is existed in life skills educationplanning, include determine skill education that will be implemented, hold asocialization, determine the goal, spreading questionnaire, determine execution time,optional skill education curriculum, pre-pare media and infrastructure.

\section{The Education Model Based on Life Skill}

The concept of life skills refers to three categories of thought models, namely; pragmatic thinking models; realisticempirical thinking models; and idealist-normative thinking model which in principle is complementary to one thought with another thought. According to Dalsgaard (2014) stated that pragmatism is often construed as one school of thought, but there have been a number of different and to some extent incongruent interpretations of even fundamental assumptions in the field from the very beginning. In the pragmatic thinking models, Cavaleri (2005) found that It is a systems thinking and pragmatic knowledge-creating processes are both defined by their grounding in how things actually work in practice. In systems thinking, dynamic models of cause and effect are created to show how interactions among system elements produce emergent and unintended behaviors. On the other hand, in the studies Changwong, et al. (2018) found that the experimental group had higher average scores in terms of critical thinking ability and academic achievement, and its members were satisfied with a high level of the model 
performance, particularly, with the instructor's use of the developed learning materials.

The method generally used in teaching of life skills in secondary level involves the process of participatory learning using four basic activities like practical activities, feedback and reflections activities, consolidation and reinforcement activity and practical application in day to day life situations (Munsi and Guha, 2014).

The present study of the NIMHANS model of life skills program is a suitable and an effective school mental health program. The highlights of the model/program are as follows: comprehensive health including mental health through psychosocial competence in adolescents is the goal to empower the adolescent; using life skills as the medium/process; providing a structure to the program by activities; and teachers as life skills educators/facilitators (Srikala and Kishore, 2010).

In the conceptual model for contributing to the healthy development of young: a life skills approach. Ozmete (2019) stated that a key aspect of human development as important to basic survival as intellect is the acquisition of socio-cognitive and emotional coping skills. This approach, sometimes referred to as skills-based education, builds skills in these particular areas to strengthen an young' protective factors, promote the competencies necessary to make a healthy transition to adulthood, and promote his or her adoption of positive behaviors. Effective programs focuses skills to issues relevant to an young's developmental tasks and social context, such as personal development, understanding peer relations, or managing emotions.

While other life skills education models, stated by Cornell University Cooperative Extension Programme and Iowa State University Extension Programme aim youth development. The programmes develop to a Target Life Skills (TLS) model for evaluating youth development experiences. The model includes some subtitle such as health, mental, emotional, physical. The Target Life Skills Model is intended to be inclusive for all possible life skills.

As for Badru (Dinesh and Belinda, 2014) building a life skills model through the Social Learning Theory Developed. It is one of models in the teaching of life skills . In this model, where The methods used tofacilitate this active involvement include working in small groups and pairs, brainstorming, role play, games and debates. A life skills lesson may start with a teacher exploring with the students what their ideas or knowledge is about a Particular situation in which a life skill can be used.

\section{METHODOLOGY}

The analytical methode used is meta-synthesis analysis. These methode using aims to identify, evaluate and interpret similar research results by combining various primary data in obtaining new concepts or in-depth understanding.

In this study the author will be conduct a meta synthesis (identifying, evaluating and interpreting) 13 research journals based on life skills education, so that the authors get new concepts or deep new insights about Life Skills-Based Education Models. The author will conclude a lot of information from 13 journals that may conflict with each other or support each other which then can increase the streght of the authors analysis.

This meta-ynthesis uses qualitative techniques to summarize research findings from several types of studies that have been carried out so as to obtain results and summarize research results in general

\section{RESULT AND DISCUSSION}

In research to classify journals using meta synthesis, based on the type of publication, research design, data sources, and research findings. Then from the findings of 13 journals related to life skills, the process of reading, review and analysis has been carried out. The 13 journals that have been identified through quantitative and qualitative research, i.e Erawan, 2010; Niaraki \& Rahimi, 2013; Damirel \& Dagyar, 2016; Hanewinkel \&Abhauer, 2004; Yadav \& Iqbal, 2009; Murthy, 2016; Suminar, et.al., 2016; Kumar, 2017; Prajapati, 2017; Munsi \& Guha, 2014; Meyer, 2016; Hajizadehanari, et.al., 2013; Rahmani, 2019. In the author classification, year and type of publication can be stated in the table below:

TABLE 1.AUTHOR(S), YEAR OF PUBLICATION, AND PUBLICATION TYPES

\begin{tabular}{|l|c|c|}
\hline \multicolumn{1}{|c|}{ Author(s) } & $\begin{array}{c}\text { Year of } \\
\text { Publication }\end{array}$ & $\begin{array}{c}\text { Publication } \\
\text { Types }\end{array}$ \\
\hline Erawan & 2010 & Journal \\
\hline Niaraki \& Rahimi & 2013 & Journal \\
\hline Damirel \& Dagyar & 2016 & Journal \\
\hline Hanewinkel \&Abhauer & 2004 & Journal \\
\hline Yadav \& Iqbal & 2009 & Journal \\
\hline Murthy & 2016 & Journal \\
\hline Suminar, et.al. & 2016 & Journal \\
\hline Kumar & 2017 & Journal \\
\hline Prajapati & 2017 & Journal \\
\hline Munsi \& Guha & 2014 & Journal \\
\hline Meyer & 2016 & Journal \\
\hline Hajizadehanari, et.al. & 2013 & Journal \\
\hline Rahmani & 2019 & Journal \\
\hline
\end{tabular}

Discussion about life skills education has been done by many scholars. It even becomes the most important part in improving the quality of education of students in facing real life. According to Suminar, et al. (2016) stated that the conceptual design study model based on the four pillars, namely syntactic pattern learning, social systems and norms prevailing atmosphere of learning, reaction of the management pattern of learning interaction, support systems, facilities, materials and learning environment, the impact of the companion instructional and learning outcomes of education life skills education program.

Rahmani (2019) stated that life skills training improves student mental health; teaching life skills improves student self-esteem; the effect of education on life skills on physical symptoms, anxiety and insomnia has been meaningful, but there has been no significant effect on social dysfunction and 
depression; and the effect of life skills training on general selfesteem, social self-esteem, and academic self-esteem was meaningful. But it was not significant on family selfesteem.

Whereas Prajapati, et al. (2017) give argumnet that imparting life skills education to the students, can be helpful as it specifically addresses the needs of children, helps in motivating, providing practical, cognitive, emotional, social and self-management skills for life adjustments. Life skills education, have found to be an effective psychosocial intervention strategy for promoting positive social, and mental health of adolescents which plays an important role in all aspects such as strengthening coping strategies and developing self-confidence and emotional intelligence, as well as enhancing critical thinking, problem solving and decision making skills as has been well documented in the aforementioned studies.

As for Kumar (2017) stated that life skills help in developing positive and flexible attitude for life among youngsters. Enhancing Life Skills enables us to adapt to situations and people and helps us to lead a healthy and positive life. All people have inherent Life Skills but to get the best out of them we need training and get them shaped. Life Skills are needed to-develop a dynamic self image and self esteem; improve communication skills; make better relationships and handle interpersonal problems; and boost decision making ability; make informed decisions; to deal with the challenges of day to day life; become a well adjusted person; to adapt to situations and people; to make a positive approach and not get depressed with problems; and reduce vulnerability and high risk behaviour.

Even more spesifically Hajizadehanari'a, et al. (2013) found that religious life skills training improves students' mental health. Religious life skills training improves students' self-esteem. The impact of life skills training on physical symptoms of anxiety and insomnia were significant, but the impact was insignificant on social dysfunction and severe depression in students. The effectiveness of life skills training on global self-esteem, social self-esteem and academic selfesteem was significant, but was insignificant on family selfesteem.

Yadav and Iqbal (2009) argued that the impact of life skill training on self-esteem, adjustment and empathy among adolescents, found that subjects improved significantly in post condition on self-esteem, emotional adjustment, educational adjustment, total adjustment and empathy. However, no significant difference was found on social adjustment in pre and post condition. Overall training was very efective as subjects improved in the post condition on all measures except one, thus showing that Life skill training do show positive results in bringing change in adolescent's attitude, thought and behavior by providing supportive environment to them.

Erawan (2010) states that there as a correlation between life skills and EQ. While Niaraki \& Rahimi (2013) stated that there was a significant difference between pre and post condition on all the dimensions of self-esteem, so that life skill training was effective in increasing self-esteem.

Damirel \& Dagyar (2016) states that problem-based learning has a low positive effect on students' attitudes. It means that problem-based learning is effective in helping students gain a positive attitude toward courses. Hanewinkel \& Abhauer (2004) provides the argument that prevention programmes that are run for only a few months can have a positive impact on variables considered to be protective with regard to smoking uptake.

Murthy (2016) argues that life skills program there are close links between the department and other subjects, including Science, RS, Thinking Skills, Current Affairs and Games/ PE. Life skills are also developed through assemblies, which are led by individual members of staff and by forms or other groups. A life skill encourages capacity to think rationally both inside and outside the classroom.

Munsi \& Guha (2014) found that life skill education should be framed as a well structured programme to satisfy needs and outcome based participatory learning which aims at increasing positive and adaptive behaviours among individuals on different psycho-social skills. Social structure, sense of equality, school realities and teacher capacity of a country can only determine ways to integrate Life Skills into formal education systems of that country. Training of life skills is an effective means to empower the youth to act sensibly, to take initiative and take control over the adverse situations. The method generally used in teaching of life skills in secondary level involves the process of participatory learning using four basic activities like practical activities, feedback and reflections activities, consolidation and reinforcement activity and practical application in day to day life situations.

Meyer (2016) found that Students' perceptions of their life skills were positive and that project-based learning helped them develop multiple life skills including, but not limited to communication, collaboration, problem-solving, responsibility, and time management. Implications of this research suggest that project-based learning has a positive influence on students' life skills development across rade levels and helps prepare them to be successful in the $21 \mathrm{st}$ century global community and economy.

\section{CONCLUSION}

The education model based on life skills through training can contribute to mental health, self-esteem, empathy, positive and flexible attitudes so that it affects the physical, mental and rational thinking aspects. Besides that, it can also help in developing self-confidence, emotional intelligence, improve critical thinking skills, improve communication skills, make better relationships and deal with interpersonal problems, can solve problems, reduce vulnerabilities and high risk behaviors, wiser, responsibility, time management and make positive decisions in the face of everyday. 


\section{REFERENCES}

[1] Behroz-Sarcheshmeh, Saiedeh; Karimi1, Masoud; Mahmoudi, Farideh Shaghaghi1, Parvaneh; and Jalil-Abkenar, Seyyedeh Somayyeh (2017). Effect of Training of Life Skills on SocialSkills of High School Students With Intellectual Disabilities. Journal of Practice in Clinical Psychology, Volume 5, Issues 3.

[2] Bush, T. (2011). Theories of educational leadership and management. London, UK: SAGE Publications

[3] Cavaleri, Steven A. (2005). Systems Thinking For Knowledge. World Futures Journal, Volume 61:

[4] Changwong, K.; Sukkamart, A.; and Sisan, B. (2018). Critical thinking skill development: Analysis of a new learning management model for Thai high schools. Journal of International Studies, 11(2)

[5] Dalsgaard, Peter (2014). Pragmatism and Design Thinking. International Journal of Design, Volume 8, Issues 1.

[6] Dinesh, R. and Belinda, R. (2014). Importance Of Life Skills Education For Youth. Indian Journal Of Applied Research. Volume - 4, Issue - 12

[7] Erawan, Prawit (2010). Developing Life Skills Scale for High School Students throughMixed Methods Research. European Journal of Scientific Research. Vol.47 No.2

[8] Gulhane, T. F . (2014). Life Skills Development through School Education. IOSR Journal of Sports and Physical Education (IOSR JSPE). Volume 1, Issue 6

[9] Hajizadehanari'a, Khalil; Fardb, Seyed Massoud Haji Seyed Hossini; Hajizadehanaric, Hassan; Yaghoubzadehd, Ali; Farhadiane, Ali; and Askarif, Mansoor (2013). The effectiveness of life skills education with religious approach to safety, mental health and self-esteem in elementary school students. The European Journal of Social \& Behavioural Sciences.

[10] Hanewinkel, Reiner \& Abhauer, Martin (2004) Fifteen-month followup results of a school-based life-skills approach to smoking prevention. Health Education Research Journal, Vol.19 no.2 2004

[11] J, Daisy P., and Nair, A. Radhakrishnan (2018). An Exploratory Study On Life Skills Intervention And Its Impact On The Study Skills Among Young Adolescents. International Journal of Innovations in Engineering and Technology (IJIET). Volume 10 Issue 3

[12] Juwahir (2017). Life Skills Management Development for the Students in Madrasah Aliyah State (MAN) Purwokerto 2, Banyumas Regency. Islamic Education Management Study Program, Postgraduate for Institute of Islamic State Religion. Unpublished thesis

[13] Kumar, Pradeep (2017). Morality and Life skills: The need and importance of life skills education. International Journal of Advanced Education and Research. Volume 2; Issue 4.

[14] Kumpulainen, K.; Krokfors, L.; Lipponen, L.; Tissari, V.; Hilppö, J. and Ra-jala, A. (2010). Learning Bridges Toward Participatory Learning Envi-ronments. Helsinki, Finland: Helsinki University Press

[15] Lemos, Monica (2017). Collaborative Agency In Educational Management: A Joint Object For School And Community Transformation. RAE Journal, Volume 57, Number 6.
[16] Mishal, Amit Hemant (2016). A Study of Effectiveness of Life Skill Training of Training Programme on Self-Esteem of Teacher Trainees at B.Ed. Level - Pilot Study. The International Journal of Research in Teacher Education. Volume 7, Issues 2.

[17] Munsi, Krishnendu and Guha, Debjani (2014). Status of Life Skil Education in Teacher Education Curriculum of SAARCCountries: A Comparative Evaluation. Journal of Education \& Social Policy. Vol. 1 No. 1

[18] Murthy, C. G. V. (2016) Issues, Problems and Possibilities of Life Skills Education for School Going Adolescents. The International Journal of Indian Psychology . Volume 3, Issue 3, No. 11 .

[19] Nasheeda, Aishath; Haslinda Binti Abdullah; Krauss, Steven Steven; and Nobaya Binti Ahmed (2019). A narrative systematic review of life skills education: effectiveness, research gaps and priorities. International Journal of Adolascene and Youth. Volume 24, Issues 3.

[20] Niaraki, Fahimeh Rezai \& Rahimi, Hassan (2013). Effect of Life Skill Training on Self -Esteem of High School Students in Iran. European Online Journal of Natural and Social Sciences, Vol.2, No.2

[21] Ozmete, Emine (). Building Life Skills For Empowerment Of YoungPeople: A Conceptual Analysis

[22] Prajapati, Ravindra; Sharma, Bosky; and Dharmendra Sharma (2017). Significance Of Life Skills Education. Contemporary Issues in Education Research, Volume 10, Number 1, First Quarter 2017

[23] Rahmani, Mansoureh (2019). The Effect of Life Skills Training on Mental Health and Student Self-Esteem . Global Journal of HumanSocial Science: A Arts \& Humanities - Psychology. Volume 19 Issue 4.

[24] Srikala, Bharath and Kishore, Kumar K.V. (2010). Empowering adolescents with life skills education in schools - School mental health program: Does it work?.Indian Journal Psychiatry. Volume 52, Number

[25] Suminar, Tri; Prihatin, Titi; and Syarif, Muhammad Ibnan. (2016). Model of Learning Development on Program Life Skills Education for Rural Communities. Nternational. Journal of Information and Education Technology, Vol. 6, No. 6

[26] Surya, Priadi (2011). Educational Management: Handbook for Schoo of Education Student. Department of Educational Administration, Faculty of Education, Yogyakarta State University

[27] UNICEF (2015). Review of the life programme: Maldives skills education. Error! Hyperlink reference not valid., quoted on September $10,2019$.

[28] World Health Organization (1999). Partners in Life Skills Education Geneva: Department of Mental Health World Health Organization.

[29] Yadav, Pooja and Iqbal, Naved (2009). mpact of Life Skill Training on Self-esteem, Adjustment andEmpathy among Adolescents. Journal of the Indian Academy of Applied Psychology. Vol. 35, Special Issue. 